\title{
AN EMPIRICAL ANALYSIS OF FACULTY PERFORMANCE AND PERSPECTIVES IN JAPANESE BUSINESS SCHOOLS
}

\author{
Christine Amaldas ${ }^{1}$, Avinash Shankaranarayanan ${ }^{2}$, Kiminori Gemba $^{3}$ \\ Graduate School of Technology Management, Ritsumeikan University, Japan \\ dollgirl08@gmail.com \\ Aries Greenergie Enterprise (P) Ltd, India \\ avigrid@gmail.com \\ Graduate School of Technology Management, Ritsumeikan University, Japan \\ gemba@mot.ritsumei.ac.jp
}

\begin{abstract}
The research focuses on various factors influencing intrinsic and extrinsic motivational levels in international tenured academics and contractual teaching staff in Management and Business departments towards the adoption of Management of Technology (MOT) related methodologies. A set of hypotheses were defined to deduce the relationship between teaching and adoption of MOT as a framework. This research implies that job performance of international academics strongly depends on various motivational levels. The study was conducted using the interaction survey method with in-depth personal interviews consisting of open ended questions with 250 international academics (respondents consisting of Japanese and Foreign teaching staff) chosen for the study based in Japan. Hence, policy recommendations and decision making should be dealt with prudence and pragmatism.
\end{abstract}

\section{Indexing terms/Keywords}

Academics, Intrinsic, Extrinsic, Motivational Levels, Japan and Management of Technology.

\section{Academic Discipline And Sub-Disciplines}

Management of Technology, Education, e-Learning, Innovation

\section{SUBJECT CLASSIFICATION}

Innovation in Educational Technologies

\section{TYPE (METHOD/APPROACH)}

Empirical Analysis using Qualitative and Quantitative Approaches: E.g., Survey and Interview

\section{Council for Innovative Research}

Peer Review Research Publishing System

Journal: International Journal of Management \& Information Technology

Vol.4, No.1

editor@cirworld.com

www.cirworld.com, member.cirworld.com 


\section{INTRODUCTION}

Education is considered as one of the most important developmental issues facing Asiatic countries. The youth of these countries are dependent on education as their future resources towards development of their respective societies. Management education obtained major attention and big budgets from all walks of life as an artificial scenario created to make education available to every individual's requirements and beliefs towards societal development through economic incentives. Utilizing this so called 'management based educational system', students and professionals were expected to develop themselves to ensure their future along with the future of their families and their surrounding societies. In conjunction to such an aspiration, it is believed that management studies related to students' academic excellence and professional achievements utilizes a process of systematic teaching systems imposing numerous examples from relevant business experiences. Numerous experts have very recently raised several concerns about the current state of management research and pedagogy (e.g., Porter \& McKibbin, 1988; Leavitt, 1989; Hambrick, 1994; Mintzberg \& Gosling, 2002; Pfeffer \& Fong, 2002) focusing on the lack of confluence of management research on so called management "best practices" and the lack of effectiveness of management education on performance of business students in the industries and the academia (Ghoshal, 2005: 76). Ghosal (2005), in the article raises a very different concern by arguing that academic research related to conducting business and management has had some very significant and negative influences on management. These influences have been less at the level of adoption of a particular theory and more at the incorporation, within the worldview of managers, of a set of ideas and assumptions that have come to dominate much of management research. More specifically, he suggested that by propagating ideologically inspired amoral theories, business schools have actively freed their students from any sense of moral responsibility (Ghoshal, op. cit.: 76).

Supporting research and evidences (Hambrick, 1994; Mintzberg \& Gosling, 2002; Pfeffer \& Fong, 2002) indicate that the mastery of business concepts by students lead them into business pathways taking them to the next level but miserably failing to teach them moralities and ethical values. The ultimate goal must be to go from the pretence of knowledge to the substance of knowledge with respect to teaching business concepts. This is not going to be easy as the nature of the academic process naturally favours building on the existing edifice of theory instead of starting over, on fresh ground (Ghoshal, op. cit.: 81). Business mechanisms assume that people can behave opportunistically and draws its conclusions for managing people based on that assumption can induce managerial actions that are likely to enhance opportunistic behaviour among people (Ghoshal \& Moran, 1996). Ultimately, if the trend in management theory is to be reversed, only business school academics can do so. Another theory by (Osterloh \& Frey, 2003), draws on the prescriptions of corporate governance on the assumption that managers cannot be trusted making managers less trustworthy. Due to this, many ideas and initiatives (such as the use of Six Sigma in businesses) have been generated to improve the quality of the management processes, thus, ensuring the quality of the teaching and learning processes (at least in management based education) to be competent within the context of research and development and its findings with respect to the industry. In terms of policy making, all educational policy makers must plan various strategies besides providing sufficient learning facilities (technological infrastructures) and trained academics (faculty support) within institutions equally.

This study was carried out utilizing the interaction survey method with in-depth personal interviews comprising of open ended questions with 250 international academics (participants consisting of both Japanese and Foreign teaching personnel) chosen for this study located in Japan. The instruments used in the study were specifically developed to encompass all tasks and duties based on teaching specifications utilizing the Management of Technology (MOT) framework used at the department of Business and Management Studies and the department of Information and Communications Technology (ICT). Specific elements explored were factors influencing MOT adoption and usage in teaching environments including: Gender, Skillset, Age, Class Handling, Teaching Experience and Intrinsic and Extrinsic motivation levels such as Competitiveness, Popularity of students, Passing Rates, Job Satisfaction, Teaching Interests and Workload. The discussions in this paper focus on the factors that influence the intrinsic and extrinsic motivation levels in international tenured academics and contractual teaching staff in Management and Business departments with respect to the adoption of MOT related methodologies. A set of hypotheses were defined to test the variety of variables needed to deduce the relationship between teaching and adoption of MOT as a framework.

This research implies that the job performance of the international academics strongly depends on various motivational levels with respect to their roles as international teaching staff that were inter-connected to each other. The introduction serves as an example of current teaching standards in the business domains being presently deployed in various international institutions; Section 2 relates to the review of literature discussing about the penetration of MOT as a framework, digital technologies and ICT related services responsible for the management and training of business students who are absorbed into the industries with this know-how (tacit knowledge); Section 3 defines the research question, objectives and significance of the study; Penultimate Section defines the hypotheses related to the variables tested for correctness in this study; the rest of the paper: (i) statistically explores the realms of MOT influence and adoption in various streams of teaching in various departments; (ii) provides the verification of primary and secondary data collected using the instruments defined; (iii) and the findings, limitations, delimitations and the conclusion of the study.

\section{LITERATURE}

It is every academic administrator's responsibility towards improving the quality of teaching and learning in tertiary institutions globally and across their society. Research and academic "Think Tanks" such as the Academy of Management, TERI, Stanford, Harvard, etc., need to strategize mechanisms to instigate researchers and academics in the business domains to rethink their roles with respect to societal development. While the leaders of the Academy have duly expressed their concerns about the corporate scandals, they can do much more to create a new intellectual agenda that would support James Coleman's (1992) vision of the social sciences providing actual help in what he described as "the 
rational reconstruction of society." Martin Seligman, through his actions in the American Psychological Association, has already shown what some of these actions can be (Ghoshal, op. cit.: 89). In this context, the tertiary institutions dealing with educating students in Management and Technology Infrastructure (MTI) development is responsible for implementing various educational support programs especially to inculcate the use and integration of educational technologies amongst academics and students to improve the effectiveness of the teaching and learning processes incorporated in business education. There are numerous claims that academic programs with respect to business and entrepreneurship education do not adequately prepare graduates for the "real world". Harvard Business Review for instance published an article on the subject as far back as 30 years ago (Livingston, 1971), later instigating several articles to publish on the topic since then, each offering different criticisms and recommendations (e.g., Dertouzos, Lester, \& Solow, 1989; Porter, 1980; Porter \& McKibben, 1988; Steiner \& Wells, 2000; Mintzberg \& Gosling, 2002; Pfeffer \& Fong, 2002, Ghoshal, 2005; and Bennis \& O'Toole, 2005).

Kanz and Lam (1996), takes the role of defining MOT using a more practical viewpoint as simplistic societal levelling linking the underlying use of technologies working together with people to achieve systematic methods towards applying knowledge in order to produce goods and services. Tabbada (2000), takes on higher tier of academic perspective defining MOT as an educational research tool fabricated to manage the technology components of individual product life cycles, capitalize on process technology to gain competitive advantage, and integrate product and process technologies. In this paper, MOT is defined as an educational framework that is utilized in engineering, science and management departments towards knowledge acquisition for the effective standardization and delivery of industry recognized courses as the core components in tertiary institutions. Utilizing this framework, the researcher intends to provide the necessary framework for the educational intuitions and multinational organizations to gain competitive training advantages towards attaining desired levels of growth and performance on its students and future employees.

Motivation at the workplace is determined by three principles namely, intrinsic motivation, extrinsic motivation and basic psychological need (Hackman \& Oldham, 1976). Motivation refers to action, direction, intensity and behavioural persistence (Gordon et al., 1983). The Two-Factor theory explored by (Herzberg, 1968, 1966) puts stress on the importance of intrinsic and extrinsic motivations levels wherein psychologists indicate that intrinsic motivation is the direct result relationship between employees and their work which is usually self-instigating. Extrinsic motivation is formed based on the external environment of the workplace usually controlled by several variables directly or indirectly by several levels of stakeholders.

The relationship between extrinsic and intrinsic motivation levels indicates that when both results of intrinsic and extrinsic are attractive, it will contribute positively to the motivation levels of the individual. In this context, career planning is directly affected by the employee's motivation levels that are influenced by his or her work environment (Holden, 1990, 1991). Employees, amongst others, are influenced by several factors, like environment and ecology, perception, memory, cognitive development, emotion, behaviour and personality (Huitt, 2001). Rewards especially, can stimulate motivation and generate the actions required to do an activity (Enabou \& Tirole, 2003). At the same time, emotional and material support enable staff to become more committed (Brandt, 1995) in doing an activity. Besides that, good and close relationships between staff also influence the commitment within staff (Nordin, 1997). In relation to that, trainings given to teaching staff also improves commitment and job performance within them (Sahandri, 1998; 2008). Good communication in organizations also encourage job satisfaction, job performance and job commitment and these can be considered as assets in an organization (Sharifah \& Balan, 2001).

\section{PROBLEM STATEMENT}

The paper looks directly at the motivational levels of international academic staff and the intensity at which they are comfortable in adopting and utilizing MOT framework in their teaching and curriculum development. Hence, the research question is formulated based on the field work undertaken as follows:

"Does the adoption of MOT as a framework have any effect on the motivation levels of international academics in management related departments?"

To answer this question the following assumptions and objectives are formulated in the following sections.

\section{RESEARCH OBJECTIVES}

This study has been undertaken to: (1) examine the extent to which selected departments and groups of classes are engaged in MOT based teaching delivery; (2) determine the significance of MOT in promoting knowledge acquisition and industry exposure based growth; (3) analyze the critical factors for success of the students at the industry level; (4) assess the problems faced by small enterprises in managing technology related to job training; and (5) formulate recommendations for institutions and industry linkages towards the adoption and effective utilization of MOT based educational mechanisms. This paper is specifically linked to:

- Find out the MOT based motivation and training awareness amongst International and Local academics or teaching staff in management departments and tertiary institutions. 
- $\quad$ Find out whether there is any significant difference in MOT based motivation and training awareness among the academics with respect to their:
(a) Gender;
(b) Skillset;
(c) Age;
(d) Class Handling;
(e) Teaching Experience;
(f) Intrinsic and Extrinsic Work Motivational Factors.

- Defining the level of influence of the chosen factors towards the MOT based training amongst international academics (Amaldas et al., 2013).

- Defining whether or not there is a significant relationship between work motivation and its academic staff and their performance within the selected institution.

- $\quad$ Analyzing the work flow performance of Academics and its associative staff members.

\section{METHODOLOGY}

In social research, countless number of methodologies can be employed towards primary and secondary data collection. This includes methods such as experimental research, survey research, ethnography, phenomenological research, grounded theory, heuristic inquiry, action research, discourse analysis, feminist standpoint research, and many others (Crotty, 1998: 5). However, research in the education domain tend to make use of a selection of common methodologies, namely Experiment, Survey, Case study, Grounded theory, Ethnography and Action research, each suiting specific studies.

\section{Design of Study}

The study design encompasses both quantitative and qualitative approaches. For the quantitative approach, the survey descriptive design is used. Descriptive research, also known as statistical research, describes data and characteristics about the population or phenomenon being studied. Descriptive research answers the questions who, what, where, when, why and how... by identifying exploration, description and explanation as the three purposes of social science research (Babbie, 1989). Descriptive research classifies phenomena by providing an illustration of a variable that is to be observed using statistical determiners to perceive the distribution, pole and the data tendency. Two sets of instruments were used here: (1) Instruments for tenured academics and contractual teaching staffs and (2) The academics response instruments for the implementation and usage of MOT as a framework. The quantitative variables measured in this study are demographic backgrounds, motivation levels, roles, personal factors and environmental factors which influence the respondents' motivation. The qualitative design is used to observe the data from the open ended questions determined through the interview process. This design will provide detailed information related to the studied phenomenon and is very suitable to obtain the real illustration related to the determined variables. Merriam, (1998) writes that external validity "is concerned with the extent to which the findings of one study can be applied to other situations". Unambiguously, the qualitative design will be used to achieve the concept building and comprehension (Merriam, 1997) which are very much needed to make evaluations and to give recommendations related to the motivational levels of academic staff. Any research into adoption of teaching mechanisms and measure is a very hard job for it must take into account numerous complex elements, such as the interpersonal relationship, the conventional ethical norms of the institution, the existing management hierarchy, the policy system, common practices and so on.

\section{Hypotheses}

The hypotheses are formulated as follows:

"There is no significant difference in MOT based motivation and training awareness amongst the academics with respect to their Gender, Skillset, Age, Class Handling, Teaching Experience and Intrinsic and Extrinsic Work Motivational Factors."

The hypotheses $\left(\mathrm{Ho}_{1}-\mathrm{Ho}_{6}\right)$ tests the six variables listed above with regards to the adoption of MOT based motivation and training with respect to staff of the selected institution.

\section{Instruments used in the Study}

The instruments of study consist of the Motivation Instrument and the Role of International academics in the adoption and usage of MOT and related technologies. The Motivation Instrument and the roles of international academics are discussed: demographic information, age, experience, position, salary and awards received and intrinsic and extrinsic motivation levels related to summarizing the roles of the respondents. Both of these parts will form the cumulative score to view the performance of the selected respondents. The undertaken research is the type that involves at least two areas: the academics (or teachers) and the adoption of best teaching practices. Having considered all possible aspects of the 
research, Surveys and Interviews are selected as the possible instruments for data collection. Statistical verification is done using "Multiple sources of evidence" as the point of referencing here which is considered as the most suitable approach for the validation of data from such a 'fieldwork' study. It has been decided that Interpretivism is the theoretical perspective that lies behind the methodology chosen here. Constructionism is the epistemological view that overwhelms the entire research based on the philosophy that "meanings are constructed by human beings as they engage with the world they are interpreting with" (adapted from Crotty, 1998: 43).

The respondents for the study include all tenured and contracted international teaching staff selected from the study site. The appropriate sample size for a population-based survey is determined largely by three factors: (a) the estimated prevalence of the variable of interest - motivation levels with respect to MOT as a framework in this instance; (b) the desired level of confidence and (c) the acceptable margin of error. For a survey design based on a simple random sample, the sample size required can be calculated according to the following formula:

Where:

$$
n=t^{2} \times p(1-p) / m^{2}
$$

- $\mathrm{n}=$ the required sample size;

- $\mathrm{t}=$ confidence level at $95 \%$ (standard value of 1.96 );

- $\mathrm{p}=$ estimated prevalence of MOT adoption in the projected area;

- $m=$ margin of error at $5 \%$ (standard value of 0.05$)$.

It has been estimated that roughly $20 \%(0.2)$ of the teaching staff have some idea of utilizing MOT framework and its related ICT technologies (inclusive of digital infrastructure access and digital technology usage) to enhance teaching observed from the selected respondents. This figure has been taken from previous studies by the researcher during assessment of staff internally (academic audit). Hence, the ideal sample size determined would be approximately 246 respondents. After considering the correction factor that is, $n=n /(1+n / N)$, the number calculated is 250 . The choice of sample is made using the stratified random sampling method where the external validity of the study is high and the data generalization can be attained.

Many research methods such as observation, interviewing, conversation analysis, document analysis or life history can all be employed towards data gathering. However, in this research there is a stronger inclination towards qualitative methods than that of quantitative ones as the research is intended to explore as much of the subjects' view points as possible. In fact, a number of methods have been adopted to collect the data and information; namely observation, document analysis, interviewing and questionnaire answering. The comments made in the report are partly based on the observations and empirical experiences gained by the researchers in academic teaching. The analysis on the literature and the legislative documents are available at three levels: the policy level, administrative legislatures and the university. The rest of the data comes from the research surveys conducted during the term as an academic in the institutions using the techniques of interviews and questionnaires. The design aims to collect information for the investigation towards the adoption of MOT in teaching and curriculum development as well as implementation of recommended policies. The similarities are noticeable in the content where the selection of participants is made randomly within each faculty based on their inclination to divulge information to aid the study. Moreover, all faculties in the university have their representatives to participate in the survey, so that an overall picture of 'MOT adoption' can be realized.

There are two major groups participating in the survey: Tenured Staff and Contractual Staff, currently working in all major faculties: Information Management, Management Studies, Accounting \& Finance and Strategic Management \& Organization. English Language and Linguistics faculty was excluded because of the totally different Human Resource Management (HRM) principles regulated and employed by the University. The backgrounds of the two groups of respondent's are namely tenured and contractual staff. Tenured teaching staff is found to be in the ages ranging between 35 and 59. They have been working at the university for at least 10 years. All tenured staff are either the Heads of their departments or the Program Heads. Half of them have doctorates and the rest are postgraduate degree holders. Some of them are concurrently undertaking higher positions in the university's management hierarchy namely Deans of different faculties, Vice Presidents and the President of the University. The position of the tenured staff in the management gives an implication that their response to the interview and their comments certainly reflect highly on the creditability and accuracy of the data collected.

Contractual teaching staff is found to be in the ages ranging between their mid or late thirties. Their working time length at the university is relatively short, ranging between a few months to 3 years. Most of them have a Bachelor's degree and half of them are attending a Master course towards fulfilling contractual obligations and teaching requirements. By policy, PhD students are not offered any teaching position in the selected Japanese institution as a norm and are utilized mostly as teaching aid or assistants. They are allocated specific roles and tasks to be executed and are always monitored by tenured or higher ranking managers.

\section{FINDINGS AND DISCUSSIONS}

From the surveys and interviews conducted, the following observations were made pertaining to the institution under study. Every year a specific budget is allocated for the teaching and learning processes, increasing the hope that a better educational system can be benefited by all students in the selected Institution A. The survey instrument was pretested by the faculty at the authors' request from the Institution A selected for study. Based on this, a number of questions were reworded to improve clarity and to ensure that respondents' interpretation of the questions was consistent with the authors' intent. The final survey instrument was distributed electronically to 250 faculty members at Institution A in Japan. 
The rationale for focusing on the business schools is that these schools are at the forefront of management education, and thus, these institutions would be among the more likely to be recognized the need to incorporate MOT and related technologies into their curricula.

Table 1. Survey of Faculty in the Selected Institution A

\begin{tabular}{|lcc|}
\hline \multicolumn{1}{|c}{ Survey Questions } & Faculties & $\begin{array}{c}\text { Responses } \\
(\%)\end{array}$ \\
1. Usage of ICT / MOT tools such as Computer, & 33 & 15 \\
$\quad \begin{array}{l}\text { PowerPoint, Interactive Software or e-Learning tools. } \\
\text { 2. Encouraging students to use these tools. }\end{array}$ & 52 & 22 \\
3. Course Notes and Online Information Content. & 22 & 11 \\
4. Student's interaction in class and in Virtual Classroom & 11 & 7 \\
sessions. & & 20 \\
5. Others & 49 & 10 \\
$\quad \begin{array}{l}\text { A. Never heard of MOT Technologies/have no idea on } \\
\quad \text { how to define it. }\end{array}$ & 21 & 3 \\
B. All of the above \\
$\quad$ promoted with the student and faculties.
\end{tabular}

To obtain a data set representative of a cross-section of business disciplines, proportionate stratified sampling was used based on faculty disciplines as identified from Institution A's Faculty pages. Respondents were, however, asked to report their actual area of expertise during the survey conducted. A performance gap was observed between the students and staff at these departments which is still considered wide. This situation is caused by the lack of quality in the basic facilities of learning and the related teaching services which is still unsatisfactory. This can well be observed through the lack of course material updates; lack of teacher training and moderation; rigid rules and management problems; peer pressure and other issues. Hence, many academics admit that they lack the skills in teaching due to lack of support materials, limited guidance and staff training given. This situation should encourage policy makers to give more diligent attention in providing educational technologies (MOT related as it is the case here) related training and services to academics. It is intended that this will give direct influence through examination results and career opportunities. Besides directly providing MOT as a framework, staff and administrators are also responsible for ensuring the level of comprehension and Skillset of academics related to MOT by always updating themselves with the latest trends. In relation to this, the responsibilities and tasks that are needed to complete all tasks by administrators and their network of academic staff are perceived as being hectic with heavy workloads. Without the support of internal management and continuous motivation, whether intrinsically or extrinsically within the department, it is difficult for the goal to be realized. In addition to this, there are various issues that challenge the credibility and mental endurance of the administrators such as complaints of academics on the lack of opportunities of being exposed to the trainings of teaching support materials and the lack of demand from departments towards teaching support materials that are produced by their associated heads of managers.

Strictly speaking, the success of implementing any management or technology based programs is an effort to ensure the quality of education depending fully on the effort and the initiative of the management and their staff. It is very important that the administrators of the organization obtain a complete illustration on the motivation levels of their academics be it intrinsic or extrinsic. All the factors leading to motivation needs to be explored and researched so that it can be manipulated to help improve the academics' motivations. In relation to this, the study is an initiative for exploration of some of those aspects, which later contribute meaningful data to the policy makers towards planning and decision making. Based on the field work spanning institutions in the Asiatic regions of Japan, all MIT and Business related department staff in their respective tertiary institutions were utilized towards data collection. The research work undertaken is based on a mixed mode approach where the collected data is analyzed using a triangulated verification methodology. The data collection methodology applied includes Personal Interviews, Surveys and Questionnaires employed during the author's involvement as a staff member in the respective institutions. The names of these institutions are not being disclosed here due to contractual obligations when undertaking this research. Hence, for simplicity the tertiary intuition (International University in Japan) here on will be referred to as Institution A.

Institution A, comprises of 250 respondents (134 permanent teaching staff and 116 contractual teaching staff as our respondents out of approximately 400 teaching staff) playing an important role in internationalizing the curriculum and bringing international university degree programs and related content to students in the selected departments. The institution is affiliated to the Ministry of Education in Japan and has its ties to numerous international University linkages such as Australia, Singapore, India, China and Malaysia inculcating international management perspectives and technological superiority. Thus, programs and activities of all Management related institutions depended a lot on commitment, work culture and satisfaction, competency, attitude and motivation of all its staff and students involved.

A total of 12 questions with Likert Scale were administered to all respondents. As pointed out in the methodology section of the paper, the list of questions has already been field-tested by other researchers in Japan. As all students at Institution A are assumed to be exposed to its MOT promotion curriculum and teaching, a positive rise in the use of IT would indicate that Institution A has indeed succeeded in its educational aims. The analysis of the field data was carried out to explicate 
the reasons for the lack of MOT acceptance and usage among staff and students. For analyzing the data, the 't-test' and one way ANOVA were used for evaluating the gathered data proving the stated hypotheses.

Table 2(a,b,c). Frequency Distribution and Cross Tabulation

(a.) Faculty Type and Frequencies

\begin{tabular}{|ll|r|r|r|r|}
\hline & & Frequency & Percent & Valid Percent & $\begin{array}{c}\text { Cumulative } \\
\text { Percent }\end{array}$ \\
\hline \multirow{3}{*}{ Valid } & International Faculty & 114 & 45.6 & 45.6 & 45.6 \\
& Contractual Staff & 136 & 54.4 & 54.4 & 100.0 \\
& Total & 250 & 100.0 & 100.0 & \\
\hline
\end{tabular}

(b.) Motivation Frequencies

\begin{tabular}{|rl|r|r|r|r|}
\hline & Frequency & Percent & Valid Percent & \multicolumn{1}{c|}{$\begin{array}{c}\text { Cumulative } \\
\text { Percent }\end{array}$} \\
\hline \multirow{3}{*}{ Valid } & High & 157 & 62.8 & 62.8 & 62.8 \\
& Low & 93 & 37.2 & 37.2 & 100.0 \\
& Total & 250 & 100.0 & 100.0 & \\
\hline
\end{tabular}

(c.) Motivation of Faculty, Type, High/Low Crosstabulation

\begin{tabular}{|c|c|c|c|c|c|c|}
\hline \multicolumn{3}{|l|}{ Faculty Type } & \multicolumn{3}{|c|}{ Motivation } & \multirow[t]{2}{*}{ Total } \\
\hline & & & Intrinsic & Extrinsic & N/A & \\
\hline \multirow{3}{*}{ International Faculty } & \multirow{2}{*}{ Motivation } & High & 20 & 33 & 19 & 72 \\
\hline & & Low & 11 & 19 & 12 & 42 \\
\hline & Total & & 31 & 52 & 31 & 114 \\
\hline \multirow{3}{*}{ Contractual Staff } & \multirow{2}{*}{ Motivation } & High & 22 & 45 & 18 & 85 \\
\hline & & Low & 8 & 30 & 13 & 51 \\
\hline & Total & & 30 & 75 & 31 & 136 \\
\hline \multirow{3}{*}{ Total } & \multirow{2}{*}{ Motivation } & High & 42 & 78 & 37 & 157 \\
\hline & & Low & 19 & 49 & 25 & 93 \\
\hline & Total & & 61 & 127 & 62 & 250 \\
\hline
\end{tabular}

\section{Hypotheses Testing}

The formulated hypotheses $\left(\mathrm{Ho}_{1}\right.$ to $\mathrm{Ho}_{6}$ ) were tested for MOT based Motivation and Training Awareness of Academics based on the following variables: Gender and Educational Qualification, Age, Class Handling, Teaching Experience and Intrinsic and Extrinsic Work Motivational Factors (Refer to their frequency distribution and cross tabulation in table 2a, b, and $\mathrm{c}$ ). To test the Hypothesis $\mathrm{Ho}_{1}$ and $\mathrm{Ho}_{2}$ based on the testing variables: Gender and Educational Qualification (skill-set) the Means, Standard Deviations (SD) and p-values were calculated. From Table 3, the P-value was calculated as 0.006 which was found to be a significant difference between male and female academics in MOT based motivation and training awareness at 0.05 levels of significance. Hence, the null hypothesis is rejected.

From Table 3 based on testing variable Skill-set, the p-value was calculated as 0.317 which was found to be insignificant. Hence no significant difference between ICT and Social Science academics with respect to MOT based motivation and training awareness at 0.05 level of significance. Consequently, the null hypothesis $\mathrm{Ho}_{2}$ is accepted. To test hypothesis $\mathrm{Ho}_{3}$ (Variable Age), one way ANOVA was used for evaluation. The P-value was found to be 0.037 which is significant at 0.05 levels of significance. It indicates that there is a significant difference amongst the academics when MOT based motivation and training awareness is concerned with respect to their age. It indicates academics within the age groups of $25-30$ and 30 - 35 years of age $(m=1.40)$ have greater MOT based motivation and training awareness compared to other age groups of academics: academics greater than 40 years $(m=1.35)$ and $35-40$ years $(m=1.35)$. The $P$-value $(0.037)$ was found to be significant. Therefore, the null hypothesis $\mathrm{Ho}_{3}$ is rejected.

The reason for academics (between 25 - 35 years) are having greater MOT based motivation and training awareness is because they attend special educational workshops, service-training, refresher and orientation courses conducted by third party trainers and institutional level linkages which facilitates their field experiences to gain wider MOT adoption. It is also debatable that these academics belong to a Generation X (Catalyst, 2012) series classification which makes them more inclined towards MOT training and susceptible to technology adoption than their predecessors.

To test hypothesis $\mathrm{Ho}_{4}$ based on Class Handling, one way ANOVA was used as shown in Table 3 . The P-value of 0.037 which is found to be significant at 0.05 levels. It indicates that there is a significant difference among the academics involved in MOT based motivation and training awareness with reference to their class handling. It indicates that the Strategic Management \& Operations class handling academics $(m=1.47)$ have greater MOT based motivation and training awareness when compared with other class handling academics, specifically, Management Studies $(\mathrm{m}=1.32)$, 
Accounting and Finance $(m=1.38)$ and Information Management $(m=1.32)$, with the F-value $(0.464)$ which is found to be significant. As a result, the null hypothesis $\mathrm{Ho}_{4}$ is rejected.

Table 3. Mean, SD, and T-values for the Variables Tested

\begin{tabular}{|c|c|c|c|c|c|c|}
\hline $\begin{array}{l}\text { Grouping } \\
\text { Variable }\end{array}$ & Groups & $\mathbf{N}$ & Mean & SD & F-Value & $\begin{array}{c}\text { P-Value } \\
\text { at } 0.05\end{array}$ \\
\hline \multicolumn{7}{|c|}{ Testing for Variable: Gender \& Skillset } \\
\hline \multirow{2}{*}{ Gender } & Male & 121 & 1.38 & 0.48 & \multirow{2}{*}{0.797} & \multirow{2}{*}{$0.006 *$} \\
\hline & Female & 129 & 1.36 & 0.48 & & \\
\hline \multirow{2}{*}{ Skillset } & ICT & 116 & 1.35 & 0.48 & \multirow{2}{*}{0.574} & \multirow{2}{*}{0.317} \\
\hline & Social Science & 134 & 1.39 & 0.48 & & \\
\hline \multicolumn{7}{|c|}{ Testing for Variable: Age } \\
\hline \multirow{4}{*}{ Age } & $25-30$ & 52 & 1.40 & 0.49 & \multirow{4}{*}{0.771} & \multirow{4}{*}{$0.037 *$} \\
\hline & $30-35$ & 91 & 1.40 & 0.49 & & \\
\hline & $35-40$ & 78 & 1.35 & 0.47 & & \\
\hline & Above 40 Years & 29 & 1.31 & 0.47 & & \\
\hline \multicolumn{7}{|c|}{$\begin{array}{l}\text { Testing for Variable: Class Handling } \\
\end{array}$} \\
\hline \multirow{4}{*}{ Subjects } & Information Management & 41 & 1.32 & 0.47 & \multirow{4}{*}{0.464} & \multirow{4}{*}{$0.037 *$} \\
\hline & Management Studies & 80 & 1.34 & 0.48 & & \\
\hline & Accounting \& Finance & 86 & 1.38 & 0.48 & & \\
\hline & Strategic Management \& Operations & 43 & 1.47 & 0.50 & & \\
\hline \multicolumn{7}{|c|}{ Testing for Variable: Teaching Experience } \\
\hline \multirow{4}{*}{ Years } & Up to 5 & 47 & 1.3 & 0.462 & \multirow{4}{*}{0.299} & \multirow{4}{*}{1.231} \\
\hline & $6-10$ & 76 & 1.34 & 0.47 & & \\
\hline & $11-15$ & 97 & 1.44 & 0.5 & & \\
\hline & Above 15 Years & 30 & 1.33 & 0.48 & & \\
\hline \multicolumn{7}{|c|}{ Testing for Variable: Intrinsic and Extrinsic Work Motivational Factors } \\
\hline \multirow{3}{*}{$\begin{array}{c}\text { Motivational } \\
\text { Levels }\end{array}$} & Intrinsic & 61 & 1.31 & 0.467 & \multirow{3}{*}{0.52} & \multirow{3}{*}{$0.005 *$} \\
\hline & Extrinsic & 127 & 1.39 & 0.49 & & \\
\hline & N/A & 62 & 1.04 & 0.49 & & \\
\hline
\end{tabular}

To test hypothesis $\mathrm{Ho}_{5}$ based on Teaching Experiences, one way ANOVA was used. The P-value is found to be 1.231 which is insignificant at 0.05 levels. In conclusion, there is no significant difference in MOT based motivation and training awareness of academics with respect to teaching experience. Thus, the null hypothesis $\mathrm{Ho}_{5}$ is accepted.

Similarly, to test hypothesis $\mathrm{Ho}_{6}$ based on Intrinsic and Extrinsic Work Motivational Factors, one way ANOVA was used. The Mean, SD and F-value are given in Table 3. The P-value of 0.005 is found to be significant at 0.01 levels. It indicates that there is a significant difference among the academics having MOT based motivation and training awareness with regards to Intrinsic and Extrinsic work motivational factors. It indicates that intrinsically motivated academics $(\mathrm{m}=1.31)$ have lesser MOT based motivation and training awareness compared to extrinsically motivated academics $(\mathrm{m}=1.39)$ and $\mathrm{N} / \mathrm{A}(\mathrm{m}=1.04)$ staff. The F-value of 0.52 is found to be significant and thus, the null hypothesis $\mathrm{Ho}_{6}$ is rejected.

Hence from the computed values of significance from Table 3, it can be assumed that there is a significant difference with respect to MOT based motivation and training with relevance to academics in the Japanese institution with respect to their Gender, Age, Subject Handling and Levels of Motivations towards MOT adoption and technological usage.

\section{Limitations of the Study}

Limitations identify potential weaknesses of the study. The following are some of the limitations faced by the study:

- This study was undertaken at only one of the Japanese Institutions spanning various Management courses and departments.

- $\quad$ The respondents of this study are focused on two specific groups namely: International academics (Tenured) and Contractual teaching staff. Thus, the generalization of study is limited to all the international academics in the selected institution where the researcher had worked previously.

- Studies show that the extrinsic or outer factors do not show any relevance to extrinsic motivation.

- Other institutions could have been compared but resource limitations, financing and time constraints played a bigger role in limiting the scope of the research.

\section{CONCLUSION}

Asiatic regions such as Japan with respect to international education still have scope for improving their adoption and utilization of technologies and content delivery in terms of technological development (Amaldas et al., 2012). The outcomes of MOT promotion at the selected site (Institution A) were observed in the field research as follows:

(a) MOT promotion at Institution A was largely led by policy makers and key administrative officials. 
(b) The faculty plays a subdued role with no responsibility for promotion of MOT as one of the key stakeholders of the University.

(c) MOT promotion does not reach all the students as surveyed separately by our previous research.

(d) MOT promotion policies are not coherent at Institution A; and therefore, are not adequately implemented to have the expected outcomes.

Evidently, much of the current MOT promotion policies were formulated during the planning years for the establishment of Institution A. As such, all the six courses that were made part of the curriculum were done with the purpose of complementing the overall learning at the University. They were never meant to turn out MOT experts for the industry. Once the policy makers had decided on the curriculum it is mainly implemented by the Academic Office, where the administrators were in a race against time to appoint enough lecturers (mainly contracted and part-time staff) to teach the overflowing classes of students. The curriculum of the six courses was largely determined by policy-makers in the early years, with the faculty trying to fulfill the broad descriptions given to each course in the course handbook. Thus, there has been very little coordination between what policy-makers had in mind to what was loosely implemented at the curriculum level.

It was also found that faculty passivity in the promotion of MOT is directly related to the staff recruitment policies of Institution A. As the University's policy makers had never intended to promote MOT as a specialist area in the curriculum, faculty recruitment was not fine-tuned to recruit industry and academic experts. Two tenured faculty and two contracted staff were seen as adequate in the initial years for simply teaching MOT as complementary subjects to content based courses. Eventually only one tenured faculty and two contracted staff with two additional part-time staff were used to manage the teaching of MOT subjects. Most language teaching faculty used only one program, the Web-CT for teaching. Despite the exclusion of faculty from policy making regarding MOT education, some of the faculty were concerned about the content of instruction and tried to write teaching aid materials for students. However, as they did not play an active role in the planning, they only thought about courses in the context of the classes they taught rather than curriculum reform for effective promotion of MOT education. The lack of leadership and initiatives did not allow the faculty to seriously question the content and complementary nature of MOT education at Institution A. The non-existence of coherent policies for the promotion of MOT is rather a worrying trend. In the two administrations that Institution A had undergone, none have attempted, so far, to bring together policy makers, administrators, faculty and students. Policy decisions on MOT promotion are transformed into curriculum based subjects by administrators, who themselves are not faculty members.

MOT is a process requiring a change in mindset and outlook shifting towards a more strategic mindset starting with the admissions process where there is need to improve and effectively manage technology at the policy level. Unfortunately, not all sectors of the economy would appreciate this reality with the same level of enthusiasm. High-performing enterprises and institutions would most likely rise up to the challenge and move along in accordance with the MOT framework with ease. Sadly, majority of our enterprises and institutions are still rigidly closed to the idea of changing and adapting to new paradigms which impair adoption of such frameworks at the policy level. On one hand, much work needs to be done and the pressure remains with the government to create the right environment for effective MOT adoption amongst all organizations. The challenge to academe, on the other hand, is to initiate curricular reforms that would address the MOT needs of Japan in this case. Meanwhile, businesses should be more open to collaboration where immediate monetary benefits may not be apparent and training along with international exposure from a university environment might be some sort of a luxury for its future employees.

\section{ACKNOWLEDGMENTS}

The first author would like to thank the Ritsumeikan University (RU) Scholarship Committee for nominating her as a candidate for the Scholarship Awards. This research was supported under the grants of: The Society for the Advancement of Science and Technology at Ritsumeikan (ASTER), 2012; The Ritsumeikan University KENKYU-SHOREI Scholarship (Prized Fellowships for the Doctoral Students), 2012; and GAKKAI HAPPYO GRANT, 2012. The financial aid was of great support to the field trips and the research undertaken in making this research viable.

\section{REFERENCES}

[1] Amaldas, C., Shankaranarayanan, A., and Gemba, K. 2013. "Understanding Academic Assessment Practices: A Case Study on the Impact of Western Educational Influences on Faculty \& Students in Asia", The International Journal of Creative Thinking \& Educational Research, 10, 40-51. ISSN 2301-3087.

[2] Amaldas, C., Shankaranarayanan, A., and Gemba, K. 2012. "Faculty and Students Perceptions of TILO: A Case Study of a Vietnamese Business School", The International Journal of Ethics, Leadership \& Business Management, 8, 56-66. ISSN 2301-3052.

[3] Catalyst. 2012. Generations in the Workplace in the United States \& Canada, May 1. Retrieved from http://www.catalyst.org/knowledge/generations-workplace-united-states-canada on May 23, 2013.

[4] Coleman J. S. 1992. The Vision of Foundations of Social Theory, Analyse \& Kritik, 14, pp.117-128, Westdeutsher Verlag, Opladen. 
[5] Crotty, M. 1998. The Foundations of Social Research, Allen \& Unwin, NSW.

[6] Dertouzos, M. L., Lester, R. K., and Solow, R. M. 1989. Made in America: Regaining the productive edge: 156165. New York: Harper Collins.

[7] Enabou, R. B., and Tirole, J. 2003. "Intrinsic and extrinsic motivation", Review of Economic Studies, 70, 489-520.

[8] Ghoshal, S. 2005. "Bad management theories are destroying good management practices", Academy of Management Learning and Education, 4(1): 75-91.

[9] Ghoshal, S., and Moran, P. 1996. Bad for practice: A critique of the transaction cost theory. Academy of Management Review, 21(1): 13-47.

[10] Gordon, P.H. et al. (1983). Is Teaching a profession. Bedford Way Papers, University of London, U.K.

[11] Hackman, J. R. and Oldham G. R. 1976. Motivation through the design of work: Test of a theory. Organizational Behavior \& Human performance, 16, 250-279.

[12] Hambrick, D. C. 1994. "What if the Academy actually mattered?" Academy of Management Review, 19: 11-16.

[13] Herzberg, F. 1968. "One more time: how do you motivate employees?", Harvard Business Review, 46(1), 53-62.

[14] Hertzberg, F. 1966. Work and Nature of Man. Cleveland: World Publishing.

[15] Holden, G. 1991. The relationship of self-efficacy appraisals to subsequent health related outcomes: A metaanalysis. Social Work in Health Care, 16, 53-93.

[16] Holden, G., Moncher, M. S., Schinke, S. P., and Barker, K. M. 1990. Self-efficacy of children and adolescents: A meta- analysis. Psychological Reports, 66, 1044-1046.

[17] Huitt, W. 2001. Motivation to learn: An overview. Educational Psychology Interactive. Valdosta, GA: Valdosta State University, Retrieved 2011/09/09 from http://chiron.valdosta.edu/whuitt/col/motivation/motivate.html.

[18] Kanz, J. and Lam, L. 1996. Technology, strategy and competitiveness: An institutional managerial perspective. In. G. Gaynor (Ed.), Handbook of technology management. New York: McGraw-Hill.

[19] Leavitt, H. J. 1989. "Educating our MBAs: On teaching what we haven't taught", California Management Review, 31(3): 38-50.

[20] Livingston, J. S. 1971. Myth of the well-educated manager. Harvard Business Review, January-February: 79-88.

[21] Nordin, A. 1997. Practicum guidance and supervision by lecturers and academics of hope and reality guidance: an empirical study. Academics Education Practicum seminar working paper 1997: Century Hotel, Melaka.

[22] Merriam, S. B. 1997. Qualitative Research and Case Study in Education, San Francisco: Jossey-Bass.

[23] Merriam, S. B. 1998. Qualitative Research and Case Study Applications in Education, San Francisco: JosseyBass.

[24] Mintzberg, H., and Gosling, J. 2002. "Educating managers beyond borders", Academy of Management Learning and Education: 1(1): 64-76.

[25] Osterloh, M., and Frey, B. S. 2003. Corporate governance for crooks? The case for corporate virtue. Unpublished working paper, University of Zurich.

[26] Pfeffer, J., and Fong, C. T. 2002. "The end of business schools? Less success than meets the eye", Academy of Management Learning and Education, 1, 78-95.

[27] Porter, M. E. 1980. Competitive strategy: Techniques for analyzing industries and firms. New York: Free Press.

[28] Porter, L. W., and McKibbin, L. E. 1988. Management education and development: Drift or thrust into the 21st century. New York: McGraw Hill.

[29] Sharifah and Balan 2001. The Relationship between Communication in an Organization with Job Satisfaction, Work Performance and Work Commitment, Universiti Kebangsaan Malaysia (UKM) Bangi.

[30] Sahandri, M. G. H. 1998. An Analysis of Trainee Academics Commitment Pattern, Uni. Kebangsaan Malaysia (UKM), Bangi.

[31] Sahandri, M. G. H. 2008. Academics Activity Centre (TAC) A Catalyst of Excellence. First Speech of National TAC Conference, Seremban.

[32] Steiner, T. L., and Wells, R. M. J. 2000. Integration of the business curriculum: The case of finance and marketing in a MBA program. Financial Practice and Education, Fall/Winter: 148-159.

[33] Tabbada, Jose P. 2000. Management of technology as a field of study. In E. Patalinghug, J.Tabbada \& E. Zamora, Managing technology for global competitiveness, 254-265. Quezon City: UP Press. 


\section{Authors' biography with Photo}

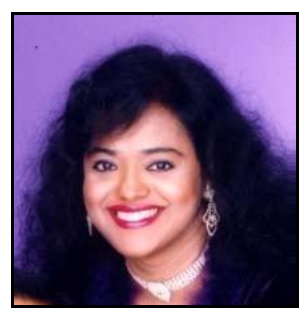

Christine Amaldas has been an internationally active researcher and academic since 2002. She has presented and presided as Program Committee Member and Program / Conference Chair over a number of International Conferences and has been invited to give guest lectures in Australia, India, Japan, Singapore, U.S.A., Vietnam and many parts of Southeast Asia. She specializes in Asia Pacific Studies, IT Governance, Security and Fraudulence, Ethics and Ethical Governance in ICT, Holistic Medicine and Energy Healing and Governance (Corporate, Public, IT and Dynamic). She has been a Peer Reviewer for International Journals. She has been actively involved in publishing several research papers and periodicals in International Conferences and Journals of high standards such as the IEEE.

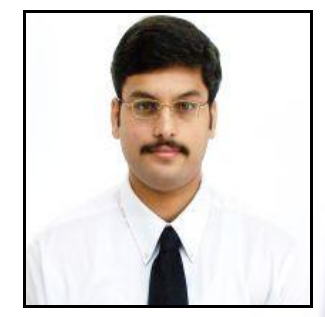

Professor Avinash Shankaranarayanan's research and teaching interests include: Applied Social \& Cognitive Psychology in Education; System Dynamics; High Performance Grid Computing; Bioinformatics; Material Flow Management; Renewable Energy Systems; Policy and Decision Making. Avinash comes from a diverse discipline of Engineering and Social Sciences, affluent in a wide range of scholarly domains specializing in Higher Education and Engineering. Since 1998, he has been holding many academic and research positions at international universities including Australia, Europe, India, Japan, Singapore \& Vietnam. He has published widely in acclaimed journals in with refereed publications spanning Education, Technology, Biotechnology, social policy, sociology, and Computational sciences. He serves as an editor and steering committee member on numerous boards including the Journal of the Environmentalist and Biologica to name a few. He is currently the Managing Director of Aries Greenergie Enterprise (P), Ltd, specializing and consulting for renewable energy and IT companies.

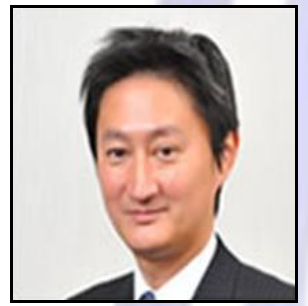

Professor Kiminori Gemba is a leading researcher in Japan and his major is Innovation Theory \& Strategic Management. His research areas include: Analyzing the Innovation Strategy of a "Service Innovation", with the main object of his research being to determine the source of the competitiveness of Service Innovations. He received his Master's degree in Engineering from the University of Tokyo followed by a $\mathrm{PhD}$ also from the University of Tokyo, where his doctoral thesis was entitled "The Dynamics of Diversification on Japanese Industries". He is currently a Professor at the Graduate School of Technology Management, Ritsumeikan University. 